\title{
Influence of particle size-shape correlation on the shear strength of scaled samples of coarse mine waste
}

\author{
S Linero University of Newcastle and SRK Consulting, Australia \\ S Fityus University of Newcastle, Australia \\ JV Simmons Sherwood Geotechnical and Research Services, Australia \\ E Azéma University of Montpellier, France \\ N Estrada University of Los Andes, Colombia \\ J Dixon Fortescue Metals Group Ltd, Australia
}

\begin{abstract}
Coarse materials like rockfill and coarse mine waste must be scalped or scaled for shear strength testing in the laboratory as the size of commercial equipment is not big enough to test the full-scale material. Samples of coarse material prepared for testing differ from their prototypes in the characteristic sizes of the particles and/or the form of the particle size distribution (PSD) curve. The representativeness of the shear strength parameter determined in the laboratory on scaled samples is questionable, nevertheless they are typically used for geotechnical design without additional consideration.
\end{abstract}

The particle shapes in a natural mine waste of colluvium sediments derived from eroded ancient sedimentary rocks from the Pilbara region of Australia was analysed and a correlation between shape and size was identified. The fragments have a particle shape ranging from slabs to sub-equant blocks with a tendency of larger particles to be flatter and platy. Therefore, material scaling for shear strength determinations inevitably alters not only the size of particles and proportion of sizes, but also the characteristic shapes of the material particles as it implies substituting larger (slabs) particles by smaller (sub-equant) particles.

The direct-shear shear strength of a prototype sample of the colluvium sediment was evaluated in the laboratory, as well as two different scaled representations (models) with reduced maximum particle size. The scaled specimens, composed of more equant fragments due to the nature of the size-shape correlation, showed lower shear strength compared with the prototype sample.

Simulations with a discrete element method reveal that the changes in the shear strength observed when altering the PSD are not due to the change in particle sizes. Instead, these changes in shear strength result from the variation of the particle shapes induced by the alteration of the PSD. This suggests that particle shape is a higher order factor than particle sizes and PSD shape on the shear strength of granular materials.

This finding highlights the importance of particle shape quantification in soil classification and its consideration in activities such as sampling, sub-sampling, and scaling of coarse materials for geotechnical testing.

Keywords: material scaling, shear strength of mine waste, particle morphology, large-scale testing

\section{$1 \quad$ Introduction}

Blasted mine waste rock and overburden materials in open pit mining with non-significant economic value have to be removed during mining production to gain access to the ore. They are transported from the pit to dumps, or in-pit backfill to allow the progress of the operation. Mine dumps may achieve hundreds of meters in height, especially in large operations and when located in mountainous terrain, as in the case of 
Rio Blanco Waste Dump in the Andina mine in Chile, which is designed to reach $900 \mathrm{~m}$ high (Palma et al. 2009).

The particle size distribution (PSD) and maximum particle size (Dmax) of coarse mine waste depend on the geology and drill and blast practices. For economic reasons, blasting is conducted so that the fragmented material has a size that suits the mining equipment. In large-scale mining, where miners increasingly opt for large capacity trucks, particles up to $2 \mathrm{~m}$ in diameter are not unusual.

Waste rock dumps are traditionally built by end-dumping over the dump face, or push-dumping (material is dumped short of the dump face then pushed to the edge by track machine). The primary geotechnical parameter required for stability design of waste rock dumps is steady state shear strength.

Evaluating the steady state shear strength of mine waste rock containing particles of metric scale is a challenging task because commercial laboratory testing devices can only accommodate samples composed of particles a few centimetres in size. The construction of larger devices for routine laboratory testing is not an option due to economic and operational constraints. To overcome equipment limitations, the mechanical properties of coarse mine waste rock materials are evaluated in the laboratory on scaled samples prepared with a reduced maximum particle size, suiting the size of available laboratory devices.

Numerical analysis to investigate the effect of only PSD alteration on shear strength, isolating the phenomenon from the influence of particle shape using the discrete element method (DEM), reveals that the steady state shear strength is invariant when altering the PSD in the specific case where the shape of the particles is kept constant across sizes and in the absence of crushing (Azéma et al. 2017a, 2017b; Estrada 2016; Voivret et al. 2009; Nguyen et al. 2015; Cantor et al. 2018).

In practice, the alteration of the PSD for scaling for physical testing is known to impact material strength. But there is no consensus in the literature as to whether scaled samples show stronger or weaker behaviour than the original material (Holtz \& Gibbs 1956; Linero et al. 2007; Ovalle 2013; Marachi et al. 1972; Marsal 1972).

This paper presents a summary of the main findings of a research project conducted to investigate when, why and how scaling of coarse granular materials affects its shear strength. Key outcomes of the project are separately published in Linero et al. $(2017,2019 c)$ and Azéma (2017a, 2017b), or under review for publication in Linero et al. (2019a, 2019b). This summary is drawn from each of these to provide specific advice to mine dump designers and operators, in a forum of geotechnical engineers who can appreciate the application of this work. A summary as such has never been put together or published before elsewhere.

\section{Methodology}

Mine waste rocks are composed of particles that can be described based on geometrical characteristics like size and morphology (Santamarina \& Narsilio 2008; Blott \& Pye 2008; Wadell 1932; Hyslip \& Vallejo 1997), as well as on mechanical characteristics like strength and specific gravity (Stimpson 1980). All these characteristics are dictated by the parental rock (Lindholm 2012), and are usually correlated among them. Because of these correlations, altering the PSD needs to be understood as an alteration of different distributions, namely: particle shape, particle strength, and particle specific gravity.

Considering the DEM results suggesting that the macroscopic shear strength is invariant when altering the PSD in samples composed of mono-shaped particles, the investigation focused on the investigation of the impact of the size-shape correlation. Following activities were undertaken:

1. Investigation of the potential size-shape correlation of a coarse mine waste rock.

2. Laboratory investigation of the shear strength of the material using samples prepared with a prototype PSD and other different scaled representations. 
3. Biaxial testing of samples using DEM, prepared to investigate the influence of a size-shape correlation on shear strength. The size-shape correlation considered was inspired in the one observed for the material analysed in the laboratory.

The material tested was an overburden material composed of eroded and transported particles (colluvium) derived from a sedimentary Precambrian-aged Banded Iron Formation (BIF), with province-wide distribution, located at the Pilbara region of Australia. The BIF formations consist essentially of alternating beds and laminae of hematite or magnetite and chert. The overburden particles had a variable composition presumably dominated by gangue. Thin layering of banding in the range of less than $1 \mathrm{~mm}$ to few centimeters was observed in saw cut and polished fragments.

The shape of the overburden particles was evaluated based on 'elongation' (breadth to length) ratio $(I / L)$, and 'flatness' (thickness to breadth) ratio (S/I), considering the standard measurement protocol proposed by Krumbein (1941). In this protocol, $L$ is the greatest distance apart of two parallel planes tangential to the particle surface, $I$ is the maximum dimension perpendicular to $L$, and $S$ is the maximum dimension perpendicular to $L$ and I. For further detail on the shape measurement, please see Linero et al. (2017).

For testing the large-scale direct shear testing facility at the University of Newcastle was used. This facility was built in 2013 and allows the investigation of square samples of up to $720 \mathrm{~mm}$, applying vertical loads of up to $4 \mathrm{MPa}$. Its boundary conditions were modified in 2017 to better comply with the testing philosophy in standards. A repeatability of the friction angle at large displacement in the range of one degree can be achieved in this facility among single tests (Figure 1).

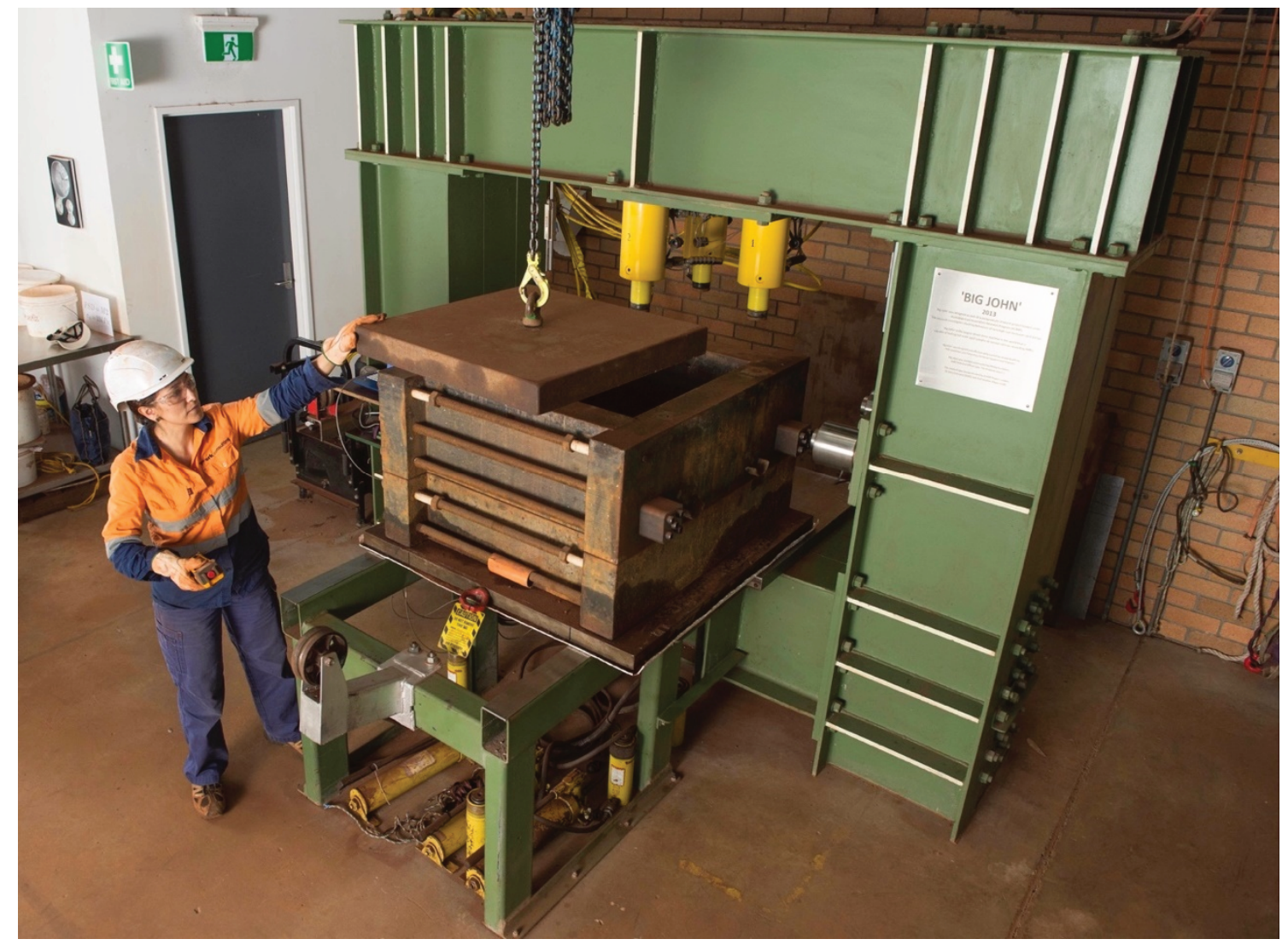

Figure 1 Overall view of the large direct shear apparatus with shear-box being positioned from the side using a mounting table, and the loading-plate being positioned using an overhead crane (Linero et al. 2019b)

Three sets of specimens where tested at different confining pressures. The first set was prepared using the original PSD of the material which was called prototype PSD. This PSD had a maximum particle size of $100 \mathrm{~mm}$. The second set was prepared using a sample scaled using a parallel gradation in logarithmic scale 
of sizes, with a maximum particle size of $19 \mathrm{~mm}(\mathrm{MH})$. The third set was prepared with a maximum particle size of $19 \mathrm{~mm}$ and a close to uniform gradation (only one size fraction) (MU). The specimens were prepared by layers, targeting a minimum density. Figure 2 allows to compare the tested PSDs.

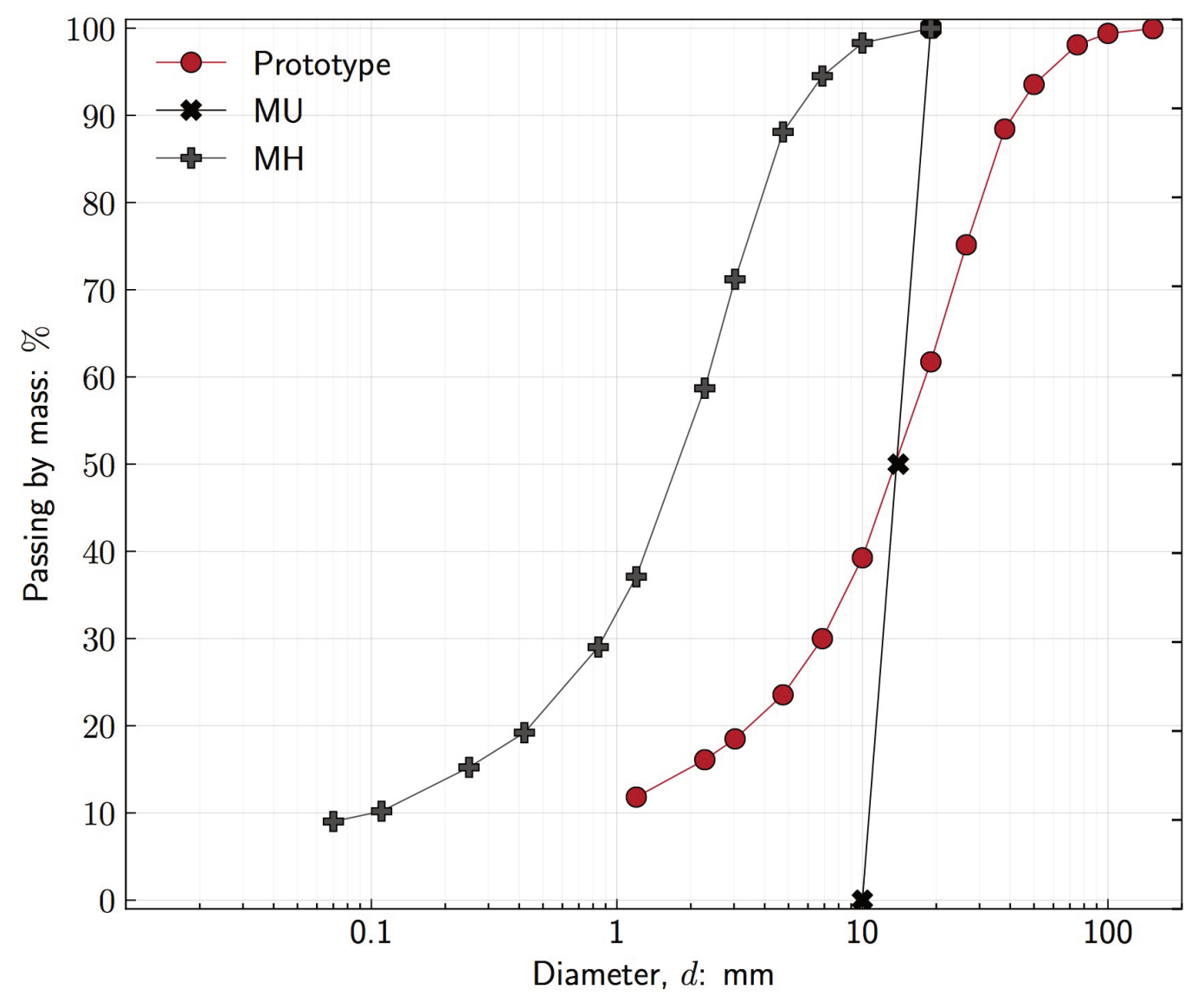

Figure 2 Comparison of the three particle size distributions tested (Linero et al. 2019a)

The DEM simulations were conducted with the contact dynamics (CD) method. CD is a discrete element approach for simulation of non-smooth granular dynamics with contact laws expressing inter-particle mutual exclusion and dry friction. $C D$ is unconditionally stable and well suited for simulating rigid particles and inter-particle frictional contacts (Dubois et al. 2018). The multi-purpose software LMGC90 was used for the simulations. It was developed in Montpelier and is capable of modelling collections of particles of arbitrary shape (https://git-xen.Imgc.univ-montp2.fr/Imgc90/Imgc90_user/-/wikis/home).

To isolate the effects of gradation and size-shape correlation of particles on steady state shear strength, two different materials were simulated. One was composed of mono-shaped particles (same shape across all sizes), and other was composed of size-shape correlated particles.

The idealised size-shape correlation imposed was inspired by the characteristics of the material analysed in Newcastle. Larger fragments in any given sample were flatter (more elongated in 2D case) than smaller fragments which were comparatively more equant. Details on the derivation of the correlation can be found in Linero et al. (2019c).

To make the DEM analysis systematic in terms of PSD variation, nine different gradations were analysed in each case (mono-shaped or size-shape correlated sample fragments (Figure 3)). Those gradations were described by the size span parameter $s$. This parameter may vary from 0 to 1 to represent uniform to infinitely polydisperse materials respectively, as deducted by Voivret (2007). 
The shape chosen to model the particles was rounded cap rectangles (RCRs) (Azéma \& Radjai 2010). Figure 4 presents close-up views of some of the specimens at the end of isotropic compression. Further details on the preparation of the samples can be found in Linero et al. (2019c).

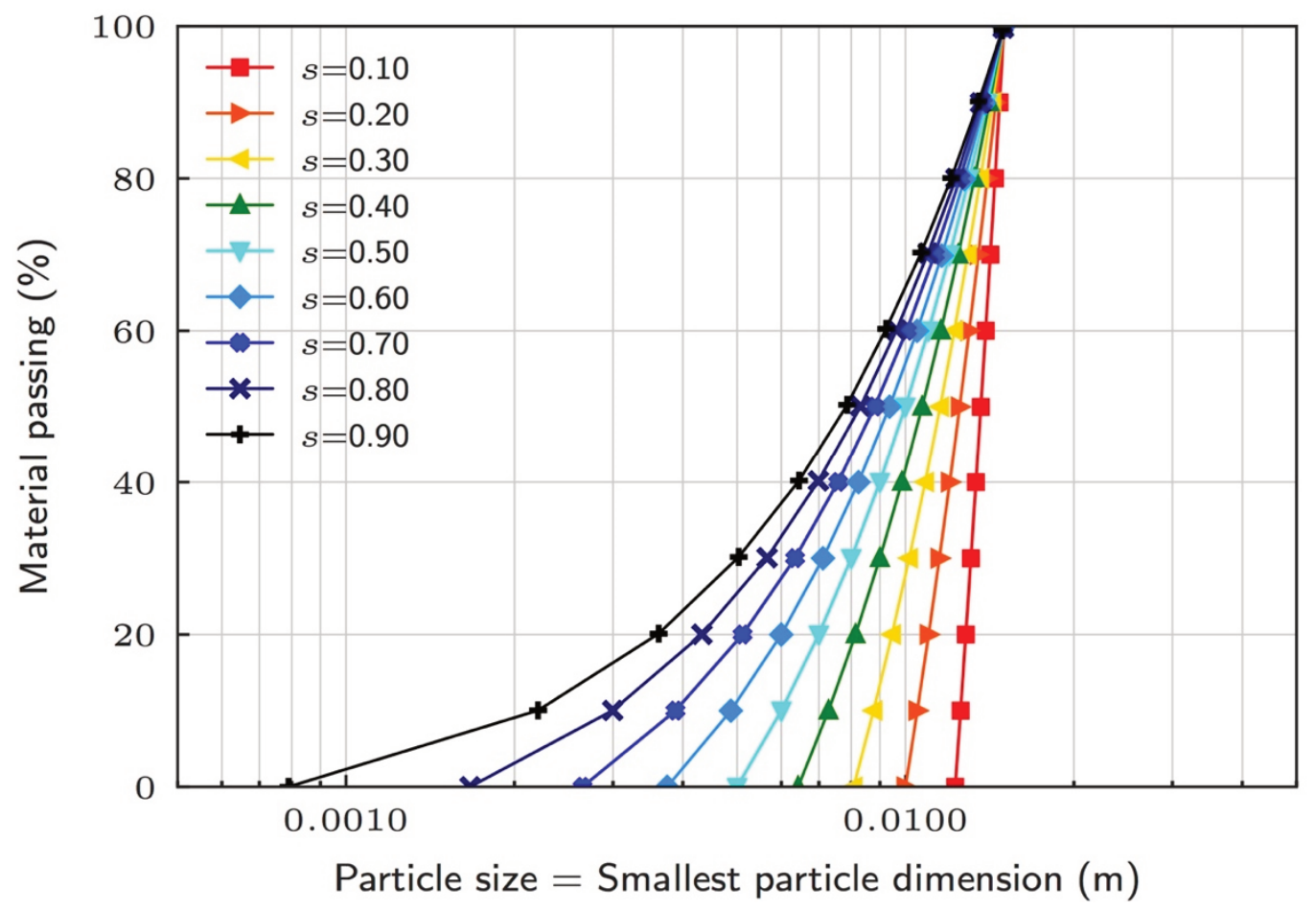

Figure 3 Particle size distributions of the nine samples evaluated in each case (mono-shaped or sizeshape correlated sample fragments). The colours illustrate the different values of size span used $s$. The limits $s \rightarrow 0$ and $s \rightarrow 1$ represent uniform and very well graded samples, respectively (from Linero et al. 2019c)

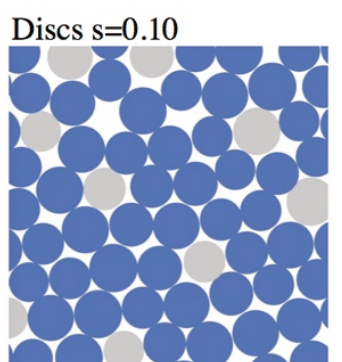

Discs $s=0.60$

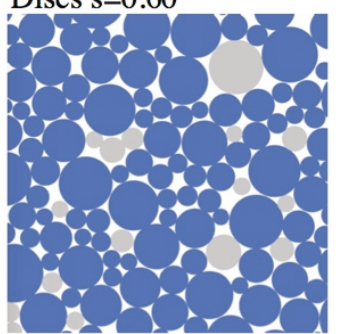

(a)

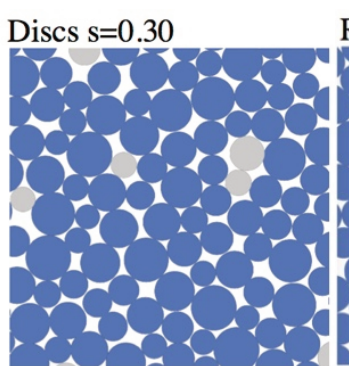

Discs $\mathrm{s}=0.90$

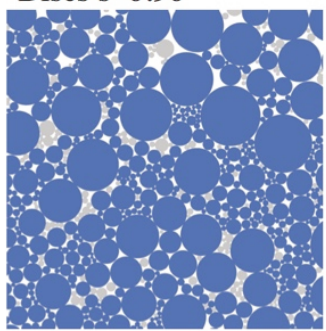

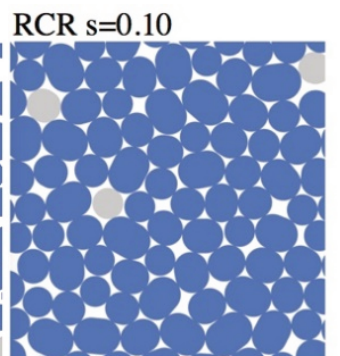

RCR $\mathrm{s}=0.60$

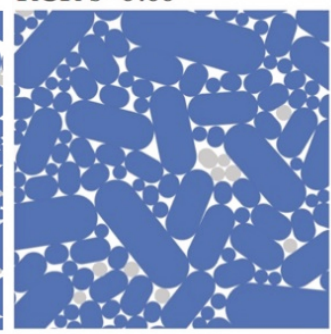

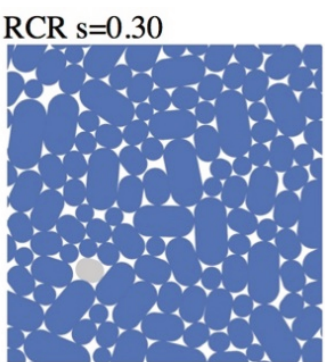

$\mathrm{RCR} \mathrm{s}=0.90$

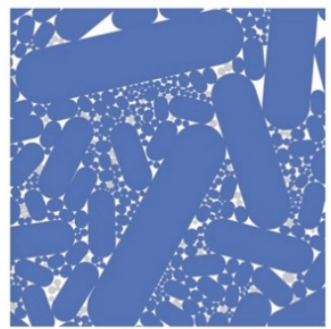

(b)

Figure 4 Close-up views of some of the samples at the end of isotropic compression. (a) Mono-shaped particles (discs series); and (b) Size-shape correlated particles (RCRs series). Grey particles represent floating particles (i.e. with zero or one contact) (from Linero et al. 2019c) 


\section{$3 \quad$ Results}

\subsection{The size-shape correlation results}

Trends in shape across particle size were observed as presented in Figure 5. In the analysed material, larger particles tend to be more flatter and platy (discoidal), than smaller particles. This outcome can be attributed to the sedimentary nature of the material, and the weakness imparted by the laminations.

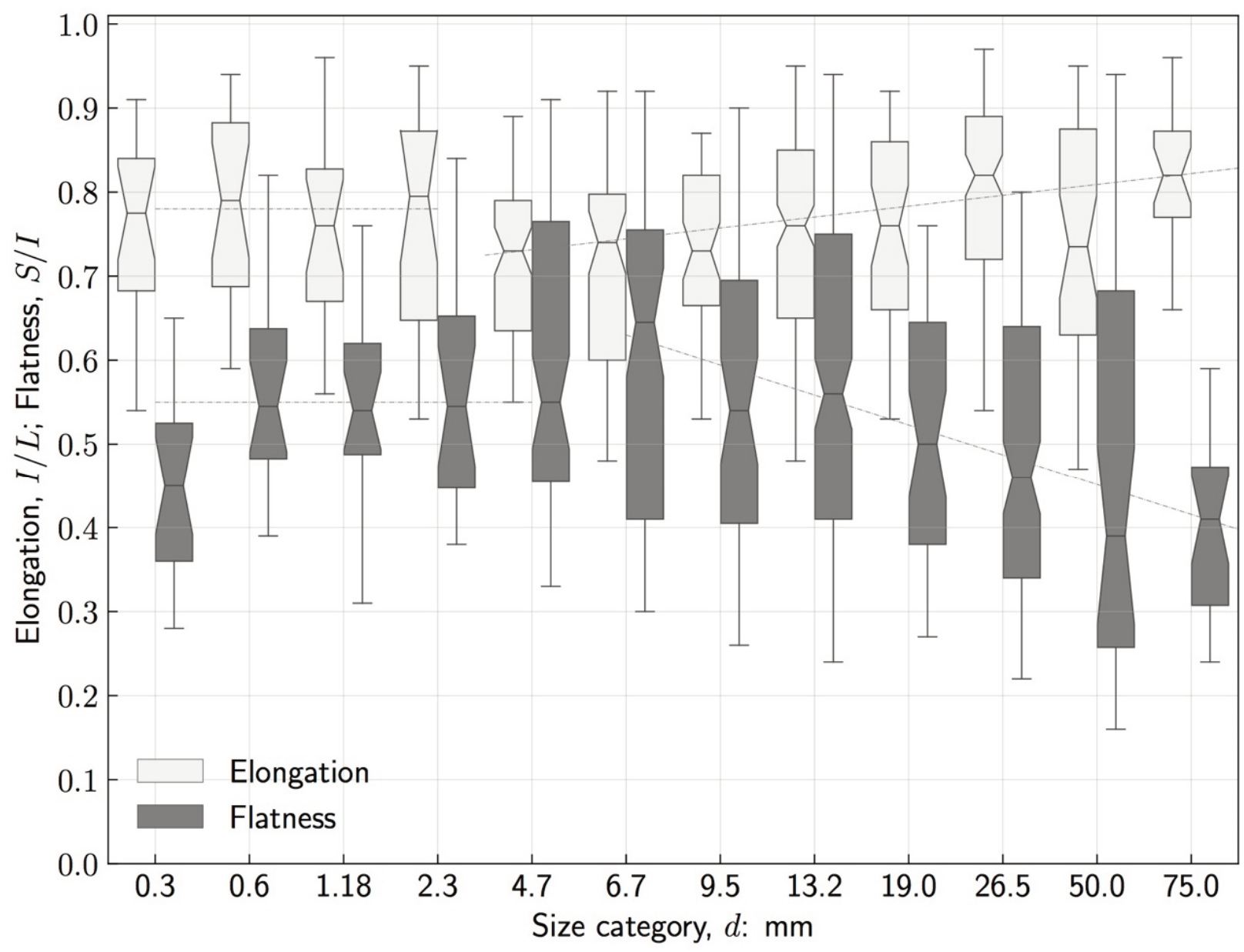

Figure 5 Box plot showing the variability of elongation ratio, and flatness ratio calculated from the form dimensions $L$ and I for the different size fractions; modified from Linero et al. (2017)

Figure 6 compares the distribution of particle shape in terms of equancy (S/L) with the distributions of particle size of the three samples tested. It is observed that samples $\mathrm{MU}$ and $\mathrm{MH}$ are preferentially composed of smaller more equant particles compare with the prototype that includes large more platy fragments.

As observed, modification of the PSD to reduce the maximum particle size (scaling) inevitably alters the characteristic shapes of the material particles because it involves removing platy particles and replacing them with blockier pieces. 


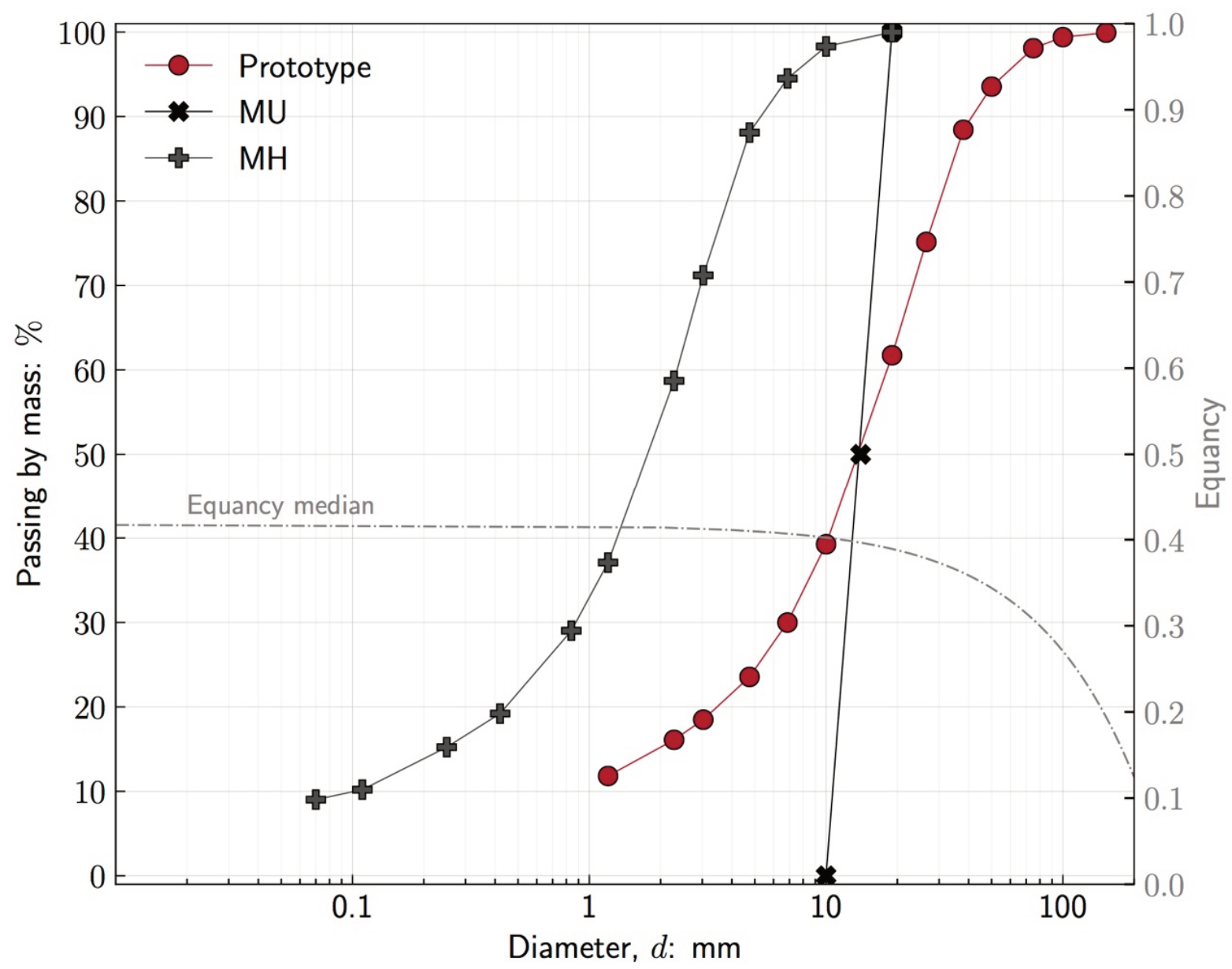

Figure 6 Comparison of the distribution of particle shape in terms of equancy (S/L) with the distributions of particle size of the three samples tested

\subsection{The direct shear testing results}

Differences on direct-shear shear strength were evidenced when comparing the results of the prototype material with the results obtained testing specimens $\mathrm{MH}$ and $\mathrm{MU}$ prepared with reduced maximum particle size as observed in Figure 7. The prototype sample with coarse gradation had higher shear strength.

The difference on the friction angle at large displacement between prototype and models $\mathrm{MH}$ and $\mathrm{MU}$ is significant, up to 5 degrees for normal stresses below $2 \mathrm{MPa}$. While $\mathrm{MH}$ and $\mathrm{MU}$ differ significantly in scale ( $D_{50}$ is different by an order of magnitude) and grading (one is uniform and the other is well graded), the strength difference between them is not significant.

In addition, it is also observed that the strength difference between prototype, $\mathrm{MU}$ and $\mathrm{MH}$ reduces (to the range of 2 degrees) at the larger stress ( $3 \mathrm{MPa}$ ). That is, the friction angle at large displacement tends to converge at large stress. 


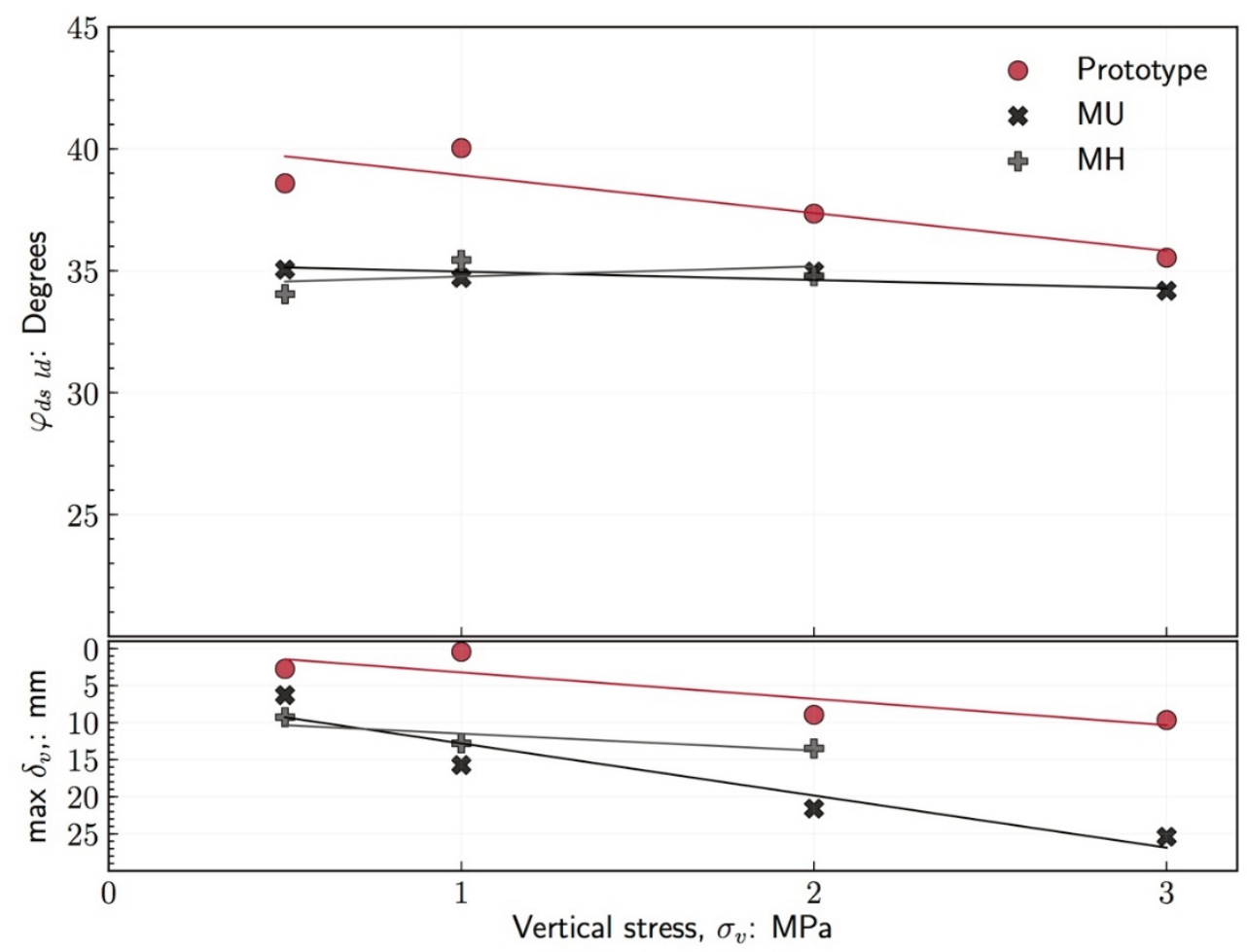

Figure 7 Comparison of the direct shear friction angle and vertical deformation at large displacement obtained for the prototype material and for models $\mathrm{MH}$ and $\mathrm{MU}$ (modified from Linero et al. 2019a)

The similarity of the friction angle at large displacement obtained for $\mathrm{MU}$ and $\mathrm{MH}$ implies that significant changes in the sizes of the particles may not necessarily impact the measure material strength. This suggest that factors other than particle size distribution may be significant for shear strength in granular materials with modified granular assemblages.

The prototype sample contained around $40 \%$ large $(>19 \mathrm{~mm})$ fragments, which are more platy than smaller fragments. In comparison, models $\mathrm{MH}$ and $\mathrm{MU}$ comprised only smaller $(<19 \mathrm{~mm})$ more consistently equant fragments, and their measured strength was significantly and consistently lower.

In contrast, there is only minor difference between the particle shapes distribution of samples $\mathrm{MH}$ and $\mathrm{MU}$ (both samples are composed of fragments with similar elongation and flatness ratio across all sizes), and despite the substantial differences in their PSDs (well graded versus uniform), the measured shear strength of these material is effectively the same.

It is noted that the direct-shear shear strength differences between the prototype and models $\mathrm{MU}$ and $\mathrm{MH}$ tended to reduce with normal stress level, when presumably the shape of the particles evolves towards more equant due to crushing under the higher stress.

Vertical deformation is much larger for model MU than for prototype, as expected, given its uniform nature. Vertical deformation for model $\mathrm{MH}$ seems to be less sensitive to stress level and sits in between the results obtained for prototype and for model MU.

\subsection{The discrete element method results}

Figure 8 shows the steady state internal friction angle $\phi s s$ (i.e. the average values in the steady state), as functions of material gradation characterised by the size span parameter $s$.

Differences on the steady state shear strength were evidenced when comparing the results obtained for specimens prepared with different gradation, using samples composed of size-shape correlated particles as 
presented in Figure 8. In contrast, the invariance of the shear strength with material gradation can be observed for the set of samples prepared with uniform particle shape.

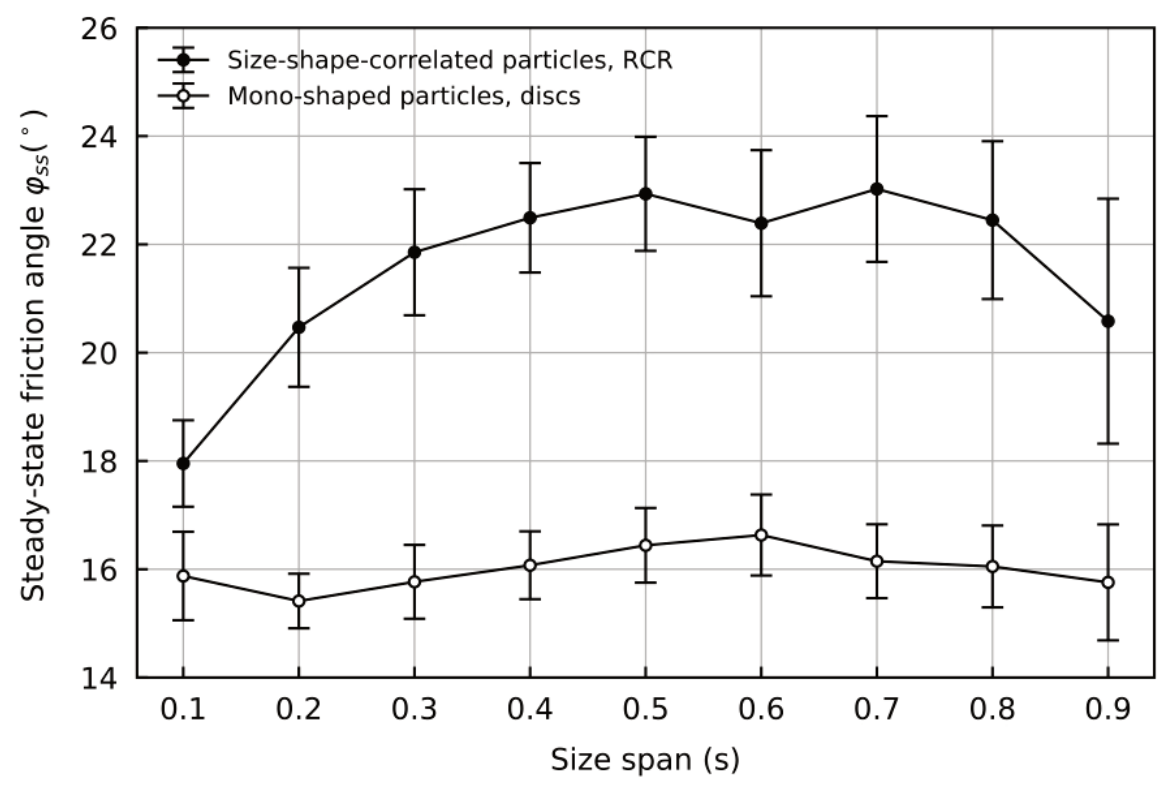

Figure 8 Comparison of steady state friction angle $\varphi s s$ as functions of the PSD size span $s$ of the two series: Series 1 composed of mono-shaped (discs) particles, and Series 2 composed of particles with size and shape correlated (RCRs). Values shown are averages of data in the steady state. The error bars capture the scatter of the readings in the DEM simulation and measure the standard deviation of the results in steady state (modified from Linero et al. 2019c)

\section{Conclusion}

Observations from this study suggest that the shear strength of coarse granular materials may be more affected by the changes in the distribution of particle shape than by changes in the distribution of particle size. It also suggests that samples composed of equant particles exhibit lower strength compared with samples containing elongated particles.

This implies, that the steady state shear strength changes observed in physical testing when the PSD is modified may be more related to the alteration in the distribution of particles' shapes than to the distribution of particles' sizes.

Therefore, the shear strength results obtained for scaled samples may be higher or lower compare with the prototype, depending in the characteristics of the size-shape correlation.

The results are important because correlations between the size and shape of natural and blasted materials due to geological and structural processes happens, as has already been described in the literature.

Hence, sampling and scaling of coarse granular materials like mine waste rock, for laboratory testing, may inadvertently cause alteration of particle shape polydispersity, making it difficult to capture the mechanical behaviour of the original material in the laboratory.

Alteration of the particle shape polydispersity in sample preparation for physical testing should be recognised and its potential implications discussed in standard geotechnical practice.

\section{Acknowledgement}

Thanks to Fortescue Metals Group Ltd. for funding this research along with SRK Consulting, the University of Newcastle and the Australian Government Department of Education and Training. This work has been also supported by the project Ecos Nord No. C19P01/63672. 


\section{References}

Azéma, E, Linero, S, Estrada, N \& Lizcano, A 2017a, 'Does modifying the particle size distribution of a granular material (i.e. material scalping) alter its shear strength?', EPJ Web of Conferences, vol. 140.

Azéma, E, Linero, S, Estrada, N \& Lizcano, A 2017b, 'Shear strength and microstructure of polydisperse packings: The effect of size span and shape of particle size distribution', Physical Review E, vol. 96, issue 2, pp. 022902-1-022902-10.

Azéma, E \& Radjai, F 2010, 'Stress-strain behavior and geometrical properties of packings of elongated particles', Physical Review E, vol. 81, issue 5, pp. 051304-1-051304-17.

Blott, SJ \& Pye, K 2008, 'Particle shape: A review and new methods of characterization and classification', Sedimentology, vol. 55, pp. 31-63.

Cantor, D, Azéma, E, Sornay, P \& Radjai, F 2018, 'Rheology and structure of polydisperse three-dimensional packings of spheres', Physical Review E, vol. 98, issue 5, pp. 052910-1-052910-11.

Dubois, F, Acary, V \& Jean, M 2018, 'The contact dynamics method: A non-smooth story', Comptes Rendus Mécanique, vol. 346, issue 3, pp. 247-262.

Estrada, N 2016, 'Effects of the grain size distribution on the packing fraction and shear strength of frictionless disk packings', Physical Review E, vol. 94, pp. 1-7.

Holtz, WG \& Gibbs, HJ 1956, 'Triaxial shear test on pervious gravelly soils', Soil Mechanics and Foundation Division ASCE, vol. 82 , pp. 1-22.

Hyslip, JP \& Vallejo, LE 1997, 'Fractal analysis of the roughness and size distribution of granular materials', Engineering Geology, vol. 48, issue 3-4, pp. 231-244.

Krumbein, WC 1941, 'Measurement and geological significance of shape and roundness of sedimentary particles', Journal of Sedimentary Petrology, vol. 11, issue 2, pp. 64-72.

Lindholm, R 2012, A practical approach to sedimentology, Springer Science \& Business Media, Berlin.

Linero, S, Fityus, S, Simmons, J \& Lizcano, A 2019a, 'Scaling of coarse granular material for shear strength determination', manuscript submitted for publication.

Linero, S, Bradfield, L, Gibson, R, Fityus, S, Simmons, J \& Lizcano, A 2019b, 'Design of a $720 \mathrm{~mm}$ square direct shear box and investigation of the impact of boundary conditions on measured strength', manuscript accepted for publication in Geotechnical Testing Journal.

Linero, S, Azéma, E, Estrada, N, Fityus, S, Simmons, J \& Lizcano, A 2019c, 'Impact of grading on steady-state strength', Geotechnique Letters, vol. 9, issue 4, pp. 328-333, 10.1680/jgele.18.00216

Linero, S, Fityus, S, Simmons, J \& Cassidy, J 2017, 'Trends in the evolution of particle morphology with size in colluvial deposits overlying channel iron deposits', EPJ Web of Conferences, vol. 140.

Linero, S, Palma, C \& Apablaza, R 2007, 'Geotechnical characterization of waste material in very high dumps with large scale triaxial testing', in Y Potvin (ed.), Proceedings of the 2007 International Symposium on Rock Slope Stability in Open Pit Mining and Civil Engineering, Australian Centre for Geomechanics, Perth, pp, 59-75.

Lindholm, R 2012, A practical approach to sedimentology, Springer Science \& Business Media, Berlin.

Marachi, ND, Chan, CK \& Seed, B 1972, 'Evaluation of properties of rock fill materials', Journal of Soil Mechanics and Foundation Division, vol. 98, issue SM1, pp. 95-115.

Marsal, RJ 1972, Resistencia y Compresibilidad de Enrocamientos y Gravas (Strength and compressibility of rock-fills), Instituto de Ingenierı, UNAM, Mexico City.

Nguyen, DH, Azéma, E, Sornay, P \& Radjai, F 2015, 'Effects of shape and size polydispersity on strength properties of granular materials', Physical Review E, vol. 91, pp. 1-9.

Ovalle, C 2013, Contribution a l'etude de la rupture des grains dans les materiaux granulaires (Contribution to the study of grain fracture in granular materials), PhD Thesis, École Centrale de Nantes, Nantes.

Palma, C, Linero, S \& Apablaza, R 2009, 'Caracterización geotécnica de materials de lastre en botaderos de gran altura mediante ensayos triaxiales y odométricos de gran tamaño' (Geotechnical characterisation of waste material in very high dumps with large-scale triaxial and odometer testing), Proceedings of the III Conferencia Sudamericana de Ingenieros Geotécnicos, International Society for Soil Mechanics and Geotechnical Engineering, Córdoba.

Santamaria, C \& Narsilio, G 2008, Clasificación de suelos: Fundamento físico, prácticas actuales y recommendations, Proceedings of the 50th Anniversary Conference, Sociedad Venezolana de Geotecnia, Venezuela.

Stimpson, B 1980, 'A suggested technique for determining the basic friction angle of rocks surfaces using core', International Journal of Rock Mechanics and Mining Sciences and Geomechanics, vol. 18, pp. 63-65.

Voivret, C, Radjai, F, Delenne, JY \& El Youssoufi, MS 2007, 'Space-filling properties of polydisperse granular media', Physical Review E., vol. 76, pp. 021301-1-021301-12.

Voivret, C, Radjai, F, Delenne, JY \& El Youssef, MS 2009, 'Multiscale force networks in highly polydisperse granular media', Physical Review Letters, vol. 102, pp. 1-4.

Wadell, H 1932, 'Volume, shape, and roundness of rock particles', The Journal of Geology, vol. 40, issue 5, pp. $443-451$. 